\title{
El rol del juez laboral en la admisibilidad del procedimiento monitorio
}

\author{
Jordi Delgado Castro* \\ Diego Palomo Vélez**
}

\begin{abstract}
RESUMEN
El procedimiento monitorio laboral se ha consolidado como uno de los instrumentos más importantes para impartir justicia en el orden laboral. Sin embargo, existen desajustes prácticos que ameritan una correcta reflexión teórica con el objetivo de proponer mejoras y criterios de interpretación acordes a la técnica monitoria. Además, este artículo realiza una propuesta a la actuación del juez en este tipo procedimental.
\end{abstract}

Procedimiento monitorio laboral - rol del juez laboral

\section{Labor for payment procedure: advocating for the best practice of the for payment procedure at the service of a better and more efficient judicial protection}

\begin{abstract}
The labor for payment procedure has established itself as one of the most important tools for justice in labor litigation. However, there are practical mismatches that call for a correct theoretical reflection with the objective of proposing improvements and interpretation criteria according to the best for payment procedure technique. In addition, this paper makes a proposal to the role of the judge in this type of proceedings.
\end{abstract}

Labor for payment procedure - role of the workers court judge

* Licenciado y Doctor en Derecho, Universidad de Barcelona. España. Profesor de derecho procesal, Universidad de Talca. Correo electrónico: jdelgado@utalca.cl.

** Licenciado en Ciencias Jurídicas y Sociales, Universidad de Talca. Doctor en Derecho, Universidad Complutense de Madrid, España. Profesor de derecho procesal, Universidad de Talca. Correo electrónico: dpalomo@utalca.cl.

Este trabajo corresponde a parte de los resultados del Proyecto de Investigación Fondecyt Regular $\mathrm{N}^{\circ}$ 1160832, titulado: "Estudio crítico del procedimiento monitorio laboral chileno: O sobre cómo un deficiente diseño legislativo puede abrir la puerta a más problemas que soluciones", del que los autores son investigadores y al que se hace presente el agradecimiento por la financiación de este estudio.

Artículo recibido el 23 de enero de 2018 y aceptado para su publicación en este número el 18 de enero de 2019. 


\section{Problema de investigación}

E 1 procedimiento monitorio laboral se incorpora a nuestro ordenamiento jurídico mediante la promulgación de la Ley N 20.087, de 3 de septiembre de 2006. Como otras instituciones que se han adoptado en nuestro ordenamiento aparece sin una acabada justificación legislativa generando muchas dudas ya antes de su implementación ${ }^{1}$. Del mismo modo, se han descrito algunos problemas en su desarrollo ${ }^{2}$ que, por lo que pareciera, conducen a su segunda reforma importante mediante la Ley $\mathrm{N}^{\mathrm{o}} 20.974$, de 3 de diciembre de $2016^{3}$.

Lamentablemente, aquellas dudas han debido ser resueltas por la jurisprudencia de forma creativa conjugando los intereses de las partes con los principios del Derecho del trabajo ${ }^{4}$. En ocasiones, entonces, las soluciones han sido más originales de lo conveniente y pareciera que algunas prácticas han sido definitivamente instauradas, formando una suerte de procedimiento monitorio nacional que, en todo caso, amerita una evaluación desde su prístino significado y desarrollo 5 . En este sentido, entonces, nos centraremos en un problema particular de este procedimiento: la fase de admisibilidad y el rol del juez. La selección de este problema responde, precisamente, a que la práctica forense ha mostrado casos que distan del origen y evolución histórica de esta técnica procedimental ${ }^{6}$.

\section{Monitorio y JUSticia ACElerada}

El procedimiento monitorio es un procedimiento sencillo y rápido ${ }^{7}$. Sin embargo, desde su instauración generó varios interrogantes, ya que sus tintes aparentemente inquisitivos

\footnotetext{
${ }^{1}$ Pereira, 2008, pp. 22-24.

${ }^{2}$ Entre otros, Concha, 2015, pp. 3 y ss.

${ }^{3}$ En rigor, se trataría de la tercera reforma tras las modificaciones incorporadas por la Ley $\mathrm{N}^{\circ} 20.260$
} y 20.287. Para su análisis, Pereira, 2008, pp. 3-5.

${ }^{4}$ Gamonal, 2013, pp. 425 y ss.

${ }^{5}$ Sin caer en consecuencia en esa tópica contraposición entre "teoría” y "práctica” en el Derecho que con el acierto al que nos tiene acostumbrados ha subrayado el profesor Andrés de la Oliva: "5. En esta misma línea, no cabe entender por 'profesionales del derecho' o 'profesionales de la justicia' a 'los prácticos', por oposición a 'los teóricos'. 'Profesionales del derecho' o 'profesionales de la justicia' son -o somos- todos los que se ocupan, o nos ocupamos, como profesión -con mayor o menor dedicación, pero profesionalmente-, en asuntos jurídicos o en los asuntos de la justicia, que son casi todos los asuntos jurídicos en cuanto pueden ser llevados a los tribunales. No se trata de desembarazarse de la incómoda y peyorativa etiqueta de 'teórico', aunque librarse de ella sea del todo justo y legítimo. Se trata de volver a pensar sin desvaríos. Pero no está de más, de paso, defender el trabajo teórico y, sobre todo, el universitario”. De la Oliva, 2004, pp. 74 y 75.

${ }^{6}$ En efecto, desde su origen alto medieval, el procedimiento monitorio surge para evadir el largo y costoso enjuiciamiento ordinario accediendo, sin cognición, a las peticiones del demandante. Su origen y renacimiento en Europa (siglo XX) siempre han estado inspirados en esa lógica (DelGAdo, 2015, pp. 23-29).

${ }^{7}$ Calamandrei, 2006, p. 209, caracterizaba a los dos modelos (puro y documental) como eminentemente sencillos: "La estructura de estos dos procedimientos no es fundamentalmente diversa: ambos, en efecto, están destinados a crear rápidamente el título ejecutivo, invirtiendo la iniciativa del contradictorio 
lo hacían distar del modelo acusatorio/adversarial impulsado desde la reforma procesal penal ${ }^{8}$. Adicionalmente, fue -desde el inicio- una figura de complejo encaje atendido el rol del juez laboral ${ }^{9}$. El sistema de resolución de los conflictos laborales determinaba una fase administrativa previa y obligatoria ${ }^{10}$ cuyo objetivo era tratar de desjudicializar el máximo número de desavenencias constituyéndose en un elemento disuasorio de la jurisdicción ordinaria ${ }^{11}$. El juez laboral también parecía impregnado de aquella idea de evitar el enjuiciamiento tradicional, y su rol ha sido discutido, en ocasiones, por tratar de llevar a extremos insostenibles su afán por remediar la desigualdad material en las relaciones laborales, mediante el Derecho del trabajo ${ }^{12}$.

En este escenario claramente inspirado y marcado por la celeridad ${ }^{13}$, el procedimiento monitorio laboral tiene por objetivo dar una respuesta rápida en determinados supuestos que, atendida su naturaleza, podríamos catalogar de simples y necesariamente urgentes ${ }^{14}$.

Por tanto, encontramos claros elementos que van dando contenido al principio formativo del proceso consagrado en el art. 425: la celeridad ${ }^{15}$.

En resumidas cuentas, se incorporó a nuestro ordenamiento procesal laboral un instituto que debiese partir de la condena del demandado (el juez acoge de inmediato ante la mera petición) en aras a dotar de un mecanismo suficientemente efectivo al trabajador que nunca está en condiciones de soportar la demora de la justicia. En la búsqueda de un punto de equilibro, el contrapeso necesario que el empleador posee es oponerse sin mayores exigencias a esa condena inmediata y, en ese caso, se abre una instancia de enjuiciamiento "más clásica", en una audiencia oral ${ }^{16}$.

sobre el deudor y utilizando como motivo de declaración de certeza del crédito la falta de reacción del deudor dentro de un término preestablecido".

${ }^{8}$ Hernández, 2012, pp. 367-369.

9 Palavecino, 2011, pp. 117 y ss.

${ }^{10}$ Orellana, 2009, p. 275. Fase que se "eliminó" del procedimiento monitorio como tal, pero que sobrevive, a la postre, debido a que se ha convertido en un requisito para accionar (OrellanA, 2010, pp. 63 y 64). También, puede consultarse cómo se modificó este engranaje entre la fase administrativa y judicial en Pereira, 2008, pp. 24 y ss.

11 Ugarte, 2008, pp. 193 y 194.

12 Palomo y Matamala, 2012, pp. 439-456.

13 Así la Ley N $\mathrm{N}^{\circ}$ 20.260, de 2008, dejó en claro que uno de sus objetivos es: Profundizar los principios de celeridad y concentración, que resultan claves para la oportuna resolución del conflicto, la que viene exigida por la naturaleza de los derechos que se reclaman en sede laboral", además de "Introducir reformas a los procedimientos monitorio y de reclamación de multas, con el fin de simplificarlos y darles un carácter más breve y expedito. Mensaje $\mathrm{N}^{\circ}$ 455-354, 2007, p. 4.

${ }^{14}$ Delgado, 2015, p. 274.

${ }^{15}$ Aspecto, este, que no siempre se cumple derivado de otras circunstancias. Un ejemplo del clásico es la parte que derechamente se oculta: queda de manifiesto en la causa del Juzgado de Letras del Trabajo de Curicó, 5.1.2016, rol M-1-2016. Procedimiento en que se acogió de inmediato la pretensión en 3 días desde su presentación, pero que, sin embargo, a enero de 2017 todavía no ha podido ser notificada. Otro ejemplo, en Juzgado de Letras del Trabajo de Temuco, 6.1.2017, rit M-5-2016.

${ }^{16}$ Hay que tener en cuenta que esa "reclamación" con la que cuenta el demandado monitorio es sencilla y ni siquiera exige fundamento. Por tanto, se trata de abrir la oportunidad de convertir al procedimiento en contradictorio, por el mero hecho de solicitarlo. Así por ejemplo, en la causa del Juzgado de Letras del 
En este último punto, lo cierto es que el monitorio laboral chileno no adoptó la clásica premisa civil o comercial en que el deudor carga con el deber de oponerse fundadamente ${ }^{17}$. Esta estructura monitoria permite al deudor generar dilaciones indebidas, sin sanción ${ }^{18}$. El monitorio laboral chileno no posee un mecanismo para equilibrar la tensión entre el derecho a ser oído y la ausencia de consecuencias jurídicas derivada de la inacción e, incluso, obstrucción al proceso del demandado ${ }^{19}$. Esta imprevisión puede provocar la generación de un expediente meramente formal y contrario a su propia naturaleza.

Confiando, así, en la colaboración real de las partes en el proceso, se instaura un procedimiento que se relaja en exigir altos estándares de lo que entendemos por debido proceso ${ }^{20}$ a cambio de entregar justicia inmediata en supuestos en que las circunstancias lo $\operatorname{ameritan}^{21}$.

\section{DE LA CELERIDAD A LAS DEMORAS INNECESARIAS}

Actualmente un procedimiento cuya vocación es la entrega rauda de la solución al conflicto $^{22}$, se caracteriza por ser rápido, pero no siempre inmediato ${ }^{23}$. En este contexto, la institución monitoria no ha terminado de arraigar completamente alguno de sus postulados en todos los tribunales del país ${ }^{24}$, como veremos en lo sucesivo.

El principal problema, del que probablemente provengan todos los demás, es la incomodidad que genera la condena inaudita altera parte ${ }^{25}$. Por formación, parece que los jueces, en ocasiones, son asaltados por la duda que supone evadir todas las etapas de los llamados momentos jurisdiccionales. Así, a la luz de lo que acontece muchas veces en la práctica forense, pareciera que no todos se sienten cómodos con arribar

Trabajo de Curicó, 11.1.2016, rit M-2-2016 el demandado solamente señaló: "solicito se cite a las partes a una audiencia de conciliación, contestación y prueba, de acuerdo a lo previsto en la norma..." y, con esta sencilla petición, el juez está obligado a llamar a audiencia. En idéntico sentido, pueden consultarse las causas: Juzgado de Letras del Trabajo de Curicó, 11.1.2016, rit M-3-2016; Juzgado de Letras del Trabajo de Curicó, 14.1.2016, rit M-4-2016 y Juzgado de Letras del Trabajo de Curicó, 14.1.2016, rit M-5-2016.

17 Como sí sucede, por ejemplo, en la conformación del último monitorio civil español tras la reforma del 2015, en que se señala que la oposición debe ser fundada, motivada y razonada (art. 815 Ley de Enjuiciamiento Civil española); o, de un modo menos enfático, pero que no resulta absolutamente libre en el art. 101 de la Ley Reguladora de la Jurisdicción Social española que exige una oposición sucinta.

${ }^{18}$ MÉndez, 2010, p. 32.

${ }^{19}$ Un ejemplar análisis de este problema en Pérez y Orellana, 2007, pp. 13-44.

${ }^{20} \mathrm{Si}$ bien es cierto que, actualmente, la doctrina es conteste a la hora de indicar que, el derecho a ser oído como parte del debido proceso, se trata de la posibilidad real de defenderse con independencia de que se ejerza o no aquel derecho. Véase, en este sentido, Bordalí, 2016, pp. 204-209.

${ }^{21}$ Calamandrei, 2006, pp. 206 y 207.

22 Ortells, 2010, p. 430.

23 Navarro, 2011, p. 54.

24 Palavecino y Ramírez, 2010, pp. 73 y ss.

${ }^{25}$ Gutiérrez-Alviz, 1978, p. 17. 
prácticamente a la fase de ejecución soslayando, de alguna forma, las fases de conocimiento y enjuiciamiento, pero precisamente esta es la característica más relevante de la técnica monitoria.

Por tanto, se produce una situación, que resulta errónea, en que cuando surge la mínima duda, el juez laboral llama inmediatamente a audiencia ${ }^{26}$. Nadie cuestiona que se trata de una previsión legal, pero no se condice absolutamente con lo que está contemplado en la tradición de esta figura y en el diseño legislativo ${ }^{27}$. A su vez, produce un problema de evaluación temprana de la teoría del caso que no parece responder al espíritu del monitorio.

\section{LAS OPCIONES DEL JUEZ ANTE UN MONITORIO: ¿ACOGE O RECHAZA?}

Lo cierto es que el principal contrasentido que se produce con nuestro monitorio laboral está, en gran parte, determinado por un diseño tímido que, unido a un cambio de paradigma, no puede sino generar dudas en los aplicadores del sistema.

El mandato que contempla el art. 500 del Código del Trabajo es claro en su primera oración: si las pretensiones están suficientemente fundadas, el juez debe acoger la demanda $y$, en caso contrario, debe rechazarla de plano ${ }^{28}$. Entonces, la clave para el demandante es consignar razones suficientes o motivos bastantes que permitan entender al juez que las peticiones no son antojadizas. A mayor abundamiento, en el derecho comparado esta es la forma en que se ha descrito el procedimiento monitorio ${ }^{29}$ (técnica ${ }^{30}$ ).

${ }^{26}$ NAVARro, 2011, p. 56.

${ }^{27}$ Ya por ejemplo en la revisión de la Historia de la Ley $\mathrm{N}^{\circ} 20.087$ que introdujo este mecanismo se puede ver diáfanamente como se entendía que: "Eso permite a trabajadores modestos, de rentas bajas, acceder a un procedimiento que se inicia en la Inspección del Trabajo con el respectivo comparendo de conciliación. Si esta no se produce, los antecedentes pasarán al tribunal del trabajo y el juez resolverá de plano" (BIBLIOTECA Del Congreso Nacional, 2006, p. 747).

${ }^{28}$ Pese a que el "primer" monitorio diseñado en la Ley N 20.087 era bastante caótico, lo cierto es que el art. 499 CT contemplaba solamente estas dos opciones y, probablemente era mucho más acertado en el punto.

${ }^{29}$ Una obra colectiva que recoge perfectamente los principales modelos europeos, RECHBERGER Y Kodek, 2001. Para muestra del Derecho comparado un ejemplo extremadamente sencillo en GARCía, 2013, pp. 59 y 60: “El proceso monitorio 'sin prueba' se caracteriza básicamente por la inexistencia de evaluación alguna del fundamento de la deuda por parte del órgano jurisdiccional. El requerimiento o mandato de pago condicionado se emite por la autoridad competente a base de la sola afirmación, unilateral y no probada del acreedor".

30 Técnicamente es tratado por parte de la doctrina como una técnica más que como un auténtico proceso (procedimiento). Esta expresión fue acuñada por LoRCA, 2000, p. 34, quien destacaba que este expediente se caracteriza por la inversión del contradictorio, por sobre otras características. Entre nosotros, LETELIER, 2015 , p. 109 , cit. 26, sintetiza claramente las ideas de la doctrina moderna al indicar: "Dudamos que el procedimiento monitorio constituya un verdadero proceso jurisdiccional, pues estamos de acuerdo en que es esencial en un proceso que la decisión jurisdiccional de relevancia sea adoptada respetando el principio -a la vez que garantía- de la bilateralidad de la audiencia. 
Además, parece lo más ajustado a un mecanismo que pretende entregar la respuesta judicial en un tiempo extremadamente breve, ahorrando el desarrollo de una o más audiencias ${ }^{31}$. Para proteger al demandado, como contrapeso de igual sencillez, simplemente basta su mera oposición para que el asunto se convierta en controvertido y deba despacharse de una forma más tradicional.

En realidad, la técnica legislativa no fue lo más preciso que encontramos en la regulación procesal del Código del Trabajo. El hecho de encontrarse, o no, una petición fundada debiese estar en íntima relación con la plausibilidad de la petición y con el grado de argumentación que gira en torno a ella. Sin embargo, alguna jurisprudencia ha venido entendiendo que se trata de la presencia $^{32}$ o ausencia de antecedentes ${ }^{33}$.

Esta forma de actuar se aleja de la tradicional técnica monitoria ${ }^{34}$, en tanto que inevitablemente el juez realiza un análisis de mérito de los antecedentes ${ }^{35}$. En esa lógica, debe entrar a observar cuán justa es la petición, o cuán ajustada a derecho, para poder tomar su decisión de acoger o rechazar. Pareciera, en esta lógica, una suerte de

31 Argumento, además, que estuvo presente a la hora de reformar el procedimiento monitorio por la Ley $\mathrm{N}^{\circ} 20.260$ (véase, Biblioteca del Congreso Nacional, 2008, pp. 10, 33, 37, 60 y 64, entre otras) Pero que, sin embargo, condujo a incorporar ese llamado a audiencia oficioso que terminó por hacer complejo el panorama.

${ }^{32}$ Un caso completamente paradigmático, en este sentido, es el contenido en la causa del Juzgado de Letras del Trabajo de San Miguel, 5.1.2016, rit M-3-2016. En esta causa, primeramente, es destacable que el acogimiento del monitorio viene precedido de una somera argumentación al más puro estilo de una sentencia; adicionalmente, en el segundo apartado de título "Vistos" enumera como "fundamento de su pretensión" un total de seis documentos individualizados allí y, concluye, entonces en el apartado tercero "Que con el mérito de los antecedentes se estiman suficientemente fundadas las pretensiones del demandante y de conformidad con lo dispuesto en el artículo 500 del Código del Trabajo, se resuelve: Que SE ACOGE la demanda". En muy parecidos términos, se pronuncia la causa del Juzgado de Letras del Trabajo de San Miguel, 6.1.2016, rit M-4-2016.

33 Así se declara recurrentemente en nuestros tribunales. Basten algunos ejemplos: sentencia del $1^{\circ}$ Juzgado de Letras del Trabajo de Santiago, 9.5.2013, rit M-499-2013; sentencia del $1^{\circ}$ Juzgado de Letras de San Carlos, 8.4.2014, rit M-9-2013; sentencia del Juzgado de Letras del Trabajo de Chillán, 22.12.2014, rit-M-322-2015; sentencia del Juzgado de Letras del Trabajo de Los Ángeles, 6.1.2016, rit M-2-2016; sentencia del Juzgado de Letras del Trabajo de Los Ángeles, 11.1.2016, rit M-4-2016; sentencia del Juzgado de Letras del Trabajo de Los Ángeles, 11.1.2016, rit M-5-2016; sentencia del $1^{\circ}$ Juzgado de Letras del Trabajo de Santiago, 4.1.2016, rit M-3-2016, y la sentencia de la Ilustrísima Corte de Apelaciones de Chillán, 3.3.2016, rol 11-2016.

${ }^{34}$ Fue Lorca Navarrete quien acuñó esta expresión. De este modo se usa la técnica monitoria "cuando los hechos aparecen claramente establecidos y parece cierto que el denunciado es el autor de la infracción" LORCA, 1988, p. 17.

${ }^{35}$ Así podemos encontrar fórmulas poco afortunadas de llamamiento a audiencia que, significativamente, implican un enjuiciamiento somero de antecedentes: "No estimándose suficientes los antecedentes aportados para emitir un adecuado pronunciamiento", en causa del Juzgado de Letras del Trabajo de San Felipe, 20.1.2016, rit M-1-2016. En parecidos términos, el Juzgado de Letras del Trabajo de Chillán señala: "sin que existan antecedentes suficientes para resolver de plano", Juzgado de Letras del Trabajo de Chillán, 2.1.2016, rit M-1-2016, Juzgado de Letras del Trabajo de Chillán, 4.1.2016, rit M-2-2016, Juzgado de Letras del Trabajo de Chillán, 5.1.2016, rit M-3-2016 y Juzgado de Letras del Trabajo de Chillán, 5.1.2016, rit M-42016. Cuestión que también observamos en las causas revisadas en 2017: Por todas, Juzgado de Letras del Trabajo de Calama, 10.1.2017, rol M-3-2017. 
prejuzgamiento que, sin duda, no se condice con los objetivos para los que fue creado el monitorio ${ }^{36}$ y, por otra parte, genera el pernicioso problema clásico del monitorio ${ }^{37}$ : juzga quien ya prejuzgó ${ }^{38}$.

La otra opción que presenta el procedimiento monitorio, a tenor de lo dispuesto en esa primera oración del artículo $500 \mathrm{CT}$, es el rechazo de plano de la demanda ${ }^{39}$. Para ello, y según lo enunciado, debe existir una ausencia de fundamentos. Entonces, nos encontraremos ante peticiones que no son razonadas y que no expresan en qué forma el demandado monitorio ha vulnerado con su actuar el ordenamiento jurídico ${ }^{40}$. En este

${ }^{36}$ Lo exponía con excelente maestría ChiovendA, 1925, p. 244: "para determinados créditos aunque no resulten de documentos, introdújose en nuestro derecho medioeval la costumbre de no citar en juicio al deudor sino de obtener directamente del juez la orden de la prestación y notificar esta al deudor: la orden era acompañada y justificada por la cláusula de que si el deudor quisiese hacer valer excepciones pudiese formular oposición dentro de un cierto término (cláusula justificativa). La oposición privaba de todo efecto a este mandatum o preceptum de solvendo (praceptum executivum sine causae cognitione) e iniciaba un juicio ordinario".

37 Bonet, 2014, pp. 104 y ss.

${ }^{38}$ Por ello, es imprescindible evitar pronunciamientos como el emitido en la causa del Juzgado de Letras del Trabajo de Valdivia, 7.1.2016, rit M-3-2016: "De los antecedentes acompañados, analizados conforme las reglas de la sana crítica, es posible inferir que el trabajador prestó servicios para la demandada por el período y remuneración que indica y que fue despedido en forma verbal sin que conste el pago de las prestaciones que reclama, de lo que se desprende la plausibilidad de la acción, razón por la cual se acogerá la demanda en la forma que se señalará en lo resolutivo". No es el momento procesal oportuno para entrar a juzgar el caso y, por lo tanto, no se podrá valorar nada conforme a las reglas de la sana crítica. El mensaje que emite el juez es impreciso al valorar por una parte (y adquirir su convicción) y hablar tan solo de plausibilidad, que en realidad es lo que el monitorio demanda. No entender esta particularidad procedimental genera la distorsión que describimos en este trabajo. Señalamos, entonces, como alternativa más ajustada a Derecho lo realizado por el Juzgado de Letras del Trabajo de Osorno en sus causas Juzgado de Letras del Trabajo de Osorno, 4.1.2016, rit M-1-2016; Juzgado de Letras del Trabajo de Osorno, 5.1.2016, rit M-2-2016; Juzgado de Letras del Trabajo de Osorno, 5.1.2016, rit M-3-2016 y Juzgado de Letras del Trabajo de Osorno, 6.1.2016, rit M-4-2016: “Que SE ACOGE, con costas, la demanda...”. Otra fórmula judicial correcta sería la empleada por el Juzgado de Letras de Puerto Montt, 4.1.2016, rit M-1-2016: "Que, de los antecedentes acompañados por el actor, se estiman suficientemente fundadas sus pretensiones y de conformidad con lo dispuesto en el artículo 500 del Código del Trabajo, se resuelve: Que se acoge la demanda (...)”; en idéntico sentido causa del Juzgado de Letras de Puerto Montt, 4.1.2016, rit M-2-2016; Juzgado de Letras de Puerto Montt, 4.1.2016, rit M-3-2016; Juzgado de Letras de Puerto Montt, 4.1.2016, rit M-4-2016 y Juzgado de Letras de Puerto Montt, 4.1.2016, rit M-5-2016. También, del mismo modo las cinco primeras causas monitorias del Juzgado de Letras del Trabajo de Castro. En parecidos términos, la causa del Juzgado de Letras del Trabajo de San Bernardo, 4.1.2016, rit M-2-2016. Con el mismo acierto de destacar lo temprano de la decisión, Juzgado de Letras del Trabajo de Talca, 4.1.2017, rol M-1-2017, que señala: "Que del mérito de los antecedentes se desprende que, en esta etapa procesal, que las pretensiones del demandante son fundadas y de conformidad con lo dispuesto en los artículos 496 y 500 del Código del Trabajo, se resuelve: Que SE ACOGE la demanda interpuesta (...)".

39 Un claro ejemplo de cómo rechazar, sin necesidad de esgrimir mayores argumentaciones, en la causa del Juzgado de Letras del Trabajo de San Miguel, 5.1.2016, rit M-1-2016: “Atendido el mérito de autos, lo dispuesto por el artículo 500 del Código del Trabajo y antecedentes aportados, SE RECHAZA la demanda interpuesta".

${ }^{40}$ No se comprende, entonces, cómo en la causa del Juzgado de Letras de Rancagua, 4.1.2016, rit M-3-2016 una demanda de diecisiete fojas y en la que se acompañan documentos fundantes (cotizaciones previsionales, justificantes de pago, planillas de asistencia, credenciales del trabajador...) que ni tan siquiera 
punto, es mucho más fácil observar cómo el acompañamiento indiscriminado de antecedentes escritos no puede convalidar la regla entregada al juez para rechazar el asunto.

De forma más sencilla: no se le puede pedir al juez que observe la cantidad y calidad de los documentos aportados para que forme su juicio y acoja la demanda ${ }^{41}$. El órgano jurisdiccional, en este evento, no está habilitado para realizar un auténtico juzgamiento del asunto ni cargar de razones a quien no pudo presentarlas ${ }^{42}$.

En este segundo escenario, parece más fácil comprender que la operación intelectual del juez pasa por una evaluación de los fundamentos y no de los antecedentes. Lo contrario, importaría un auténtico enjuiciamiento de fondo in audita altera pars. La

se exigen para tomar la decisión, fuera finalmente rechazada. Es complejo, porque vuelve a sugerir un análisis de fondo de la decisión, por una parte, y porque la resolución carece de fundamento.

${ }^{41}$ De lo contrario, se produciría algo parecido a lo descrito por NiEva a propósito de la caracterización del sistema de prueba legal o tasada en que, finalmente, los jueces terminaban literalmente "pesando" las evidencias para observar quién tenía la razón (NIEVA, 20 I 5, p. 183). Sin embargo, nuestra jurisprudencia, así lo ha entendido, en ocasiones, como en la resolución del Juzgado de Letras del Trabajo de Coyhaique, 5.1.2017, rol M-1-2017: "Que la demanda deducida aparece suficientemente fundada, atendido, especialmente, la copia de liquidación de remuneraciones del mes de diciembre de 2016, copia de la carta de término de contrato y copia del Acta de Comparecencia ante la Inspección del Trabajo de Coyhaique, de fecha 20 de diciembre de 2016, y de conformidad a lo dispuesto en los artículos 160, 162, 168, 173, 183 A y siguientes, 425, 432, 446, 454, 496 y siguientes todos del Código del Trabajo, SE RESUELVE: Que se ACOGE la demanda en procedimiento monitorio (...)". Del mismo tenor sentencia dictada en causa del Juzgado de Letras del Trabajo de Coyhaique, 5.1.2017, rol M-2-2017 del mismo tribunal. Pero no es exclusivo de este tribunal, sino que resulta una práctica bastante extendida y afianzada, sirvan como ejemplo: $1^{\circ}$ Juzgado de Letras del Trabajo de Santiago, 4.1.2017, rol M-2-2017; Juzgado de Letras del Trabajo de Antofagasta, 6.1.2017, rol M-3-2017; Juzgado de Letras del Trabajo de Arica, 20.1.2017, rol M-5-2017; Juzgado de Letras del Trabajo de Castro, 16.1.2017, rol M-2-2017; Juzgado de Letras del Trabajo de Concepción, 6.1.2017, rol M-3-2017; Juzgado de Letras del Trabajo de Copiapó, 5.1.2017, rol M-2-2017; Juzgado de Letras del Trabajo de Curicó, 11.1.2017, rol M-2-2017; Juzgado de Letras del Trabajo de Iquique, 6.1.2017, rol M-1-2017; Juzgado de Letras del Trabajo de Los Ángeles, 6.1.2017, rol M-1-2017; Juzgado de Letras del Trabajo de Puente Alto, 11.5.2017, rol M-1-2017; Juzgado de Letras del Trabajo de Puerto Montt, 9.1.2017, rol M-22017; Juzgado de Letras del Trabajo de Rancagua, 26.1.2017, rol M-2-2017; Juzgado de Letras del Trabajo de San Felipe, 17.1.2017, rol M-3-2017.

42 Precisamente, es la labor que parece entender el tribunal en causa del Juzgado de Letras del Trabajo de San Felipe, 21.1.2016, rit M-5-2016 al indicar literalmente: "No estimándose suficientes los antecedentes aportados para emitir un adecuado pronunciamiento". De peor factura técnica, pues no parece razonable que, antes de celebrarse un juicio, se le exija acreditar al demandante la relación laboral. Tenemos lo resuelto por el $1^{\circ}$ Juzgado de Letras del Trabajo de Santiago, 9.1.2017, rol M-4-2017: "Que los antecedentes acompañados por la actora resultan insuficientes para fundamentar la existencia de una relación laboral entre las partes y de conformidad con lo dispuesto en el artículo 500 del Código del Trabajo, se resuelve: Que SE RECHAZA la demanda en procedimiento monitorio (...)". Mismo tenor lo resuelto por Juzgado de Letras del Trabajo de Punta Arenas, 18.1.2017, rol M-5-2017. Al contrario, y en concordancia con nuestra tesis, parece muy razonable lo señalado en la causa del Juzgado de Letras del Trabajo de Talca, 4.1.2016, rit M-1-2016. En idéntico sentido, Juzgado de Letras del Trabajo de Talca, 5.1.2016, rit M-2-2016; Juzgado de Letras del Trabajo de Talca, 5.1.2016, rit M-3-2016; y Juzgado de Letras del Trabajo de Talca, 5.1.2016, rit M-5-2016. No sucedió lo mismo ante circunstancias parecidas en la causa del Juzgado de Letras del Trabajo de Talca, 5.1.2016, rit M-4-2016, si bien es destacable que el órgano estaba compuesto por otra juez. Apostando, entonces, por una genuina aplicación del monitorio y, acogiendo sin mayores visos de enjuiciamiento de los antecedentes, puede también consultarse: Juzgado de Letras del Trabajo de Concepción, 4.1.2016, rit M-1-2016; En términos muy evidentes, Juzgado de Letras del Trabajo de Temuco, 6.1.2016, rit M-4-2016. 
técnica monitoria se caracteriza por la inversión del contradictorio y no por cercenar la posibilidad de defensa de ninguno de los intervinientes ${ }^{43}$.

Por tanto, se puede afirmar categóricamente que en el procedimiento monitorio laboral se debiese aplicar el enjuiciamiento de las razones ${ }^{44}$ : la existencia de buenos argumentos, y no por la cantidad de antecedentes que se aporten ${ }^{45}$.

\section{El PRINCIPAL PROBlema DE DiSEÑO: El LLAMAdo A AUDIENCIA}

Ante la claridad del mandato al juez para que acoja o rechace de plano, debemos exponer cuál ha sido el elemento disruptivo del modelo. En primer lugar, literalmente el art. 500 CT habla de los antecedentes. De este modo, ha sido el propio legislador quien, quizá no muy impregnado de este modelo de enjuiciamiento ${ }^{46}$, le brindó al juez la posibilidad de citar a una audiencia cuando considerase que no existían antecedentes suficientes.

A mayor abundamiento, este escenario se hace complejo por otro mandato que se le impone al órgano jurisdiccional. Antes de señalarle la posibilidad de llamar a audiencia cuando no se sienta seguro ${ }^{47}$ : se le indica que para acoger o rechazar deberá tener en

43 Delgado y Vallespín, 2016, p. 273. Véase la aclaración que realizan respecto de la técnica monitoria, el derecho a defensa y el debido proceso.

${ }^{44}$ Es destacable el esfuerzo que realizan nuestros tribunales de justicia cuando oficiosamente rechazan procedimientos por vicios tan palpables como la incompetencia del tribunal por la inexistencia de conexión territorial de la parte demandante. Así, por ejemplo, Juzgado de Letras del Trabajo de San Felipe, 19.1.2016, rit M-4-2016 y Juzgado de Letras del Trabajo de San Bernardo, 4.1.2016, rit M-3-2016. Por otra parte, como es de suyo entenderlo, los Tribunales de Justicia deberán tener siempre a la vista las normas comunes a todo procedimiento y, por ejemplo, no dar curso a la demanda, sin tan siquiera entrar al dilema de acoger o rechazar, cuando no se constituya mandato. Véase, en este sentido, Juzgado de Letras del Trabajo de Concepción, 4.1.2016, rit M-3-2016. O, por otra, parte debe declararse la caducidad de oficio cuando esta sea percibida por el Tribunal: $1^{\circ}$ Juzgado de Letras del Trabajo de Santiago, 5.1.2016, rit M-5-2016. Incluso, nuestros tribunales con acierto exigen la corrección del procedimiento, cuando por ejemplo deben tramitarse conforme al procedimiento especial para multas administrativas (véase, $2^{\circ}$ Juzgado de Letras del Trabajo de Santiago, 4.1.2016, rit M-3-2016; $2^{\circ}$ Juzgado de Letras del Trabajo de Santiago, 4.1.2016, rit M-4-2016 y, $2^{\circ}$ Juzgado de Letras del Trabajo de Santiago, 4.1.2016, rit M-5-2016) u otros vicios (Juzgado de Letras del Trabajo de San Miguel, 7.1.2016, rit M-5-2016).

${ }^{45}$ Un caso de difícil comprensión es el acaecido en la causa del $2^{\circ}$ Juzgado de Letras del Trabajo de Santiago, 4.1.2016, rit M-1-2016, en que tras ser revocada la declaración de caducidad por la Corte de Apelaciones, el Juzgado de Letras rechazó la petición. Pareciera que se trataba de una petición, pudiésemos decir, estándar, y sin embargo el tribunal sorprende con su rechazo. Afortunadamente, la parte agraviada puede reclamar. En todo caso, es una potestad que compete exclusivamente a ese tribunal y que entra dentro del marco de lo posible. Sería esperable, eso sí, que más peticiones monitorias fueran rechazadas si se aplicase el criterio de forma constante.

${ }^{46}$ En la Historia de la Ley $N^{\circ} 20.974$ se puede leer como el Subdirector del Trabajo, Rafael Pereira Lagos, recordó que en el proyecto original esta posibilidad de llamar a audiencia no existía y, entonces, se ajustaba estrictamente a la técnica monitoria (Biblioteca del Congreso Nacional, 2016, p. 6).

${ }^{47}$ Un temor similar, parece tener el abogado patrocinante en la causa del Juzgado de Letras del Trabajo de San Felipe, 19.1.2016, rit M-3-2016, quien en su escrito de solicitud monitoria señaló: "Con relación a lo 
cuenta tres elementos: complejidad del asunto, comparecencia en la fase administrativa y la existencia de pagos liquidados por el demandado. Si bien parecieran a priori criterios razonables, lo cierto es que distan mucho de corresponderse con la técnica monitoria clásica y, al contrario, no hacen sino distorsionar la posible decisión.

El monitorio se caracteriza por acoger o rechazar y, para ello, no se debiesen tener en cuenta otros factores que el fundamento ${ }^{48}$. Pero si se van a establecer, estos tampoco parecen los más apropiados. Así, no debiese ser determinante la complejidad del asunto. En primer lugar, porque es difícil y estrictamente casuístico realizar un catastro de aquello que ha de entenderse por complejo y, subjetivamente, todos podrán considerar su asunto de alta complejidad. Normalmente los demandantes creerán que su asunto es de sencilla resolución, porque faltó el pago, o los motivos que conforman un despido justificado, por ejemplo. A su vez, porque conocer si un asunto es complejo o no, determina necesariamente la evaluación de los antecedentes aportados y hace peligrar la imparcialidad debida ante un incierto llamado a audiencia y, finalmente, porque en el derecho comparado ${ }^{49}$ no se ha conformado como un criterio relevante, sino que existe una petición que debe ser acogida, solamente cumpliéndose con criterios mayoritariamente formales.

Menos relevante, si es posible todavía, es la disposición del demandado de haber concurrido a la vía administrativa previa. Esta es una facultad que no entraña sanción y que, por tanto, goza de un grado de disposición absoluta. Mostrar voluntad a cooperar con una alternativa al proceso, no puede significar un beneficio o un perjuicio.

Finalmente, la existencia de pagos parciales tampoco parecen revelarse como motivo para acoger o rechazar el monitorio. La finalidad del monitorio es otorgar el cobro rápido de la deuda; así lo es desde sus orígenes históricos ${ }^{50}$, que debiesen trasponerse sin problemas al conflicto derivado de la relación laboral. El principal motivo es evitar una espera que, siempre, va a generar una necesidad de negociación a la baja a quien se encuentra sin disfrutar de, probablemente, su principal fuente de ingreso. El hecho de existir pagos parciales no exonera del pago íntegro de la obligación y no debiese constituirse en una especie de morigeración de los derechos del demandante.

La solución, entonces, pasa por apegarse a la literalidad de la ley y acoger toda petición que se encuentre suficientemente fundada. Esta apuesta llevaría aparejada la consecuencia de acoger prácticamente todas las peticiones acaecidas a propósito de

\footnotetext{
dispuesto en el artículo 500 del Código del Trabajo, es preciso señalar que, en el caso de autos, la pretensión que contiene la demanda, cumple con todos los requisitos exigidos por la ley para ser acogida inmediatamente. El legislador ha entregado a V.S. determinados parámetros, a efectos de clarificar esta fundamentación, y, por tanto, para acoger la respectiva demanda”. Es destacable en este caso, eso sí, que finalmente se acogió la corrección de procedimiento debido a que se excedía la cuantía. Quizá ello sí hubiera sido motivo suficiente para rechazar la petición y dejar a la parte expedita la vía procesal correspondiente. En suma, se puede señalar un cúmulo de circunstancias que solamente perjudican a la correcta administración de justicia.

48 Podría ser el monitorio documental, nada más.

49 Un buen panorama del Derecho comparado europeo y latinoamericano que reafirma nuestra observación en Nieva et al., 2015.

50 Tomás y Valiente, 1960, p. 33.
} 
un procedimiento monitorio. Y, siendo coherentes con el discurso propuesto, ello no tendría nada malo.

No debemos olvidar una cuestión que pareciera perderse de vista, no obstante su evidencia: el demandado puede reclamar. La mera oposición ${ }^{51}$ determina automáticamente la realización de la ya mencionada audiencia. Entonces, si el demandado lo pide, va a producirse una audiencia con todas las garantías en que cada parte defenderá sus intereses como mejor proceda. Por tanto no debiese cargarse al juez con la posibilidad de abrir un espacio de defensa del demandado con todas las consecuencias que este ejercicio puede terminar implicando, sino que bajo el esquema monitorio -y en rigor bajo cualquier prisma- le corresponde a este defender su derecho cuando lo considere necesario.

\section{Algunos Casos en Que SE llamó a AUdiencia}

Para la realización de este apartado tomamos, metodológicamente hablando, los cinco primeros monitorios ingresados durante el 2016 y 2017 en todos los tribunales especializados del país. De este modo, podemos realizar una suerte de etnografía aleatoria del funcionamiento del procedimiento monitorio en el ámbito laboral ${ }^{52}$.

El elemento duda o falta de antecedentes asociado a complejidad del caso parece ser el motivo que conduce al resultado que entendemos errado, es decir, el llamado a audiencia sin que las partes lo pidan. En efecto, las causas tramitadas por monitorio tienen una cuantía moderada que no permite pensar en que la trascendencia económica pueda generar distorsiones. Precisamente, este sería otro argumento para preferir una justicia que, sin complejos, otorgase este tipo de peticiones en forma casi automática.

Pero, del mismo modo que sucede en el proceso penal, es difícil imaginar que un abogado acostumbrado a litigar no presente en forma suficientemente fundada su teoría del caso $^{53}$. Un ejemplo de ello es la causa M-1-2016 tramitada ante el Juzgado de Letras de Arica en que la demanda monitoria presentaba a cabalidad el caso y, a su vez,

51 Y señalamos "mera oposición” porque basta señalar que se interpone la reclamación y, por decirlo de algún modo, los escritos son excesivamente breves y carentes de motivación. Se permite una fórmula mínima como suficiente para citar a audiencia. Puede consultarse un ejemplo, Juzgado de Letras del Trabajo de Temuco, 6.1.2016, rit M-3-2016.

52 En los siguientes tribunales durante el año 2016, los 5 procedimientos monitorios fueron acogidos (o bien, alguno adolecía de algún vicio que no permitió tramitarlo): Juzgado de Letras del Trabajo de Antofagasta; Juzgado de Letras del Trabajo de Copiapó.

${ }^{53}$ Incluso en aquellos escritos que parecen más tímidos, se suele cumplir con todos los requisitos legales y quizá solamente se percibe poca convicción en los abogados. Probablemente, sea un fenómeno motivado por el convencimiento del foro local acerca de la facilidad que los jueces tienen para llamar a audiencia. Así, por ejemplo, en causa del Juzgado de Letras del Trabajo de Valdivia, 6.1.2016, rit M-5-2016, el abogado de la Defensoría esgrime sus peticiones con poca convicción y, en especial, podemos observar que solicita la absolución de posiciones del representante señalando que esta es fortuita, pero intuyendo que se va a realizar. Por otra parte, hay ocasiones en que inexplicablemente los abogados no son suficientemente precisos y, por ejemplo, no cuantifican las prestaciones demandadas, cuestión que determina parte esencial del petitorio y 
acompañaba documentos, y para el evento de no ser acogida de inmediato ya solicitaba absolución de posiciones y exhibición de documentos. El caso es relativamente sencillo y paradigmático: un despido que principia solicitándose la nulidad, por no cumplir con los requerimientos para ser encasillado en la causal de necesidades de la empresa. Lo cierto es que la demanda da cumplimiento absoluto de lo previsto en el art. 446 CT con una detallada y circunstanciada narración de los hechos y, a su vez, las peticiones concretas que se someten al tribunal. En este contexto, lo deseable hubiera sido su acogimiento sin mayor trámite. Ahora bien, el propio demandante sabía que pudiera generar dudas en el tribunal y, realiza peticiones subsidiarias, para aquel evento ${ }^{54}$.

Ante un supuesto prácticamente incontrovertible y con hechos sencillos, finalmente, el tribunal acogió idénticamente las peticiones que fueron señaladas en la demanda. Lamentablemente, para ello transcurrieron 10 días, se generó incertidumbre, se tuvo que agendar una audiencia, y hubo que condenar en costas 55 .

De mayor complejidad resulta una forma específica de no acoger este instrumento procesal. Como señalamos, si bien no se entregan fundamentos (cuestión discutible) respecto de qué antecedentes faltan y qué dudas presenta el acogimiento de la demanda, lo cierto es que se señala que estos no existen. La fórmula utilizada, por ejemplo, por el Juzgado de Letras del Trabajo de Iquique ${ }^{56}$ es, derechamente, citar a audiencia con los apercibimientos legales previstos. Desde luego que no es de recibo que nuestros tribunales de justicia no motiven las decisiones ${ }^{57}$, pero en este contexto en que, por decirlo de algún modo, lo más sencillo pareciera ser acoger sin mayores miramientos, resulta derechamente extraño llamar a una audiencia y no señalar por qué se hace ${ }^{58}$.

Otro tópico que nos genera mucha inquietud es una forma de llamar a audiencia fundada en el art. 201 CT. En efecto, en la causa RIT M-1-2016, el Juzgado de Letras del Trabajo de Valdivia, de 5 de enero de 2016, el tribunal señaló: “A lo principal, atendida la materia y de conformidad a lo dispuesto en el artículo 174, 201 y 496 del Código del Trabajo, se resuelve: por interpuesta demanda de desafuero maternal, cítese

que, en este caso, además acarrea la elección del procedimiento correcto. En este sentido, véase, $2^{\circ}$ Juzgado de Letras del Trabajo de Santiago, 4.1.2016, rit M-2-2016.

${ }^{54}$ Llama poderosamente la atención que tanto el segundo como el tercer otrosí hacen énfasis en que para el evento de no ser acogida sin más trámite la petición, conformando de este modo una defensa eventual ante una situación que no parece generar certeza en el abogado.

${ }^{55}$ En este mismo tribunal suceden hechos prácticamente a los narrados en la causa Juzgado de Letras de Arica, 19.1.2016, rit M-4-2016; Por el contrario, sí se acogió en circunstancias casi idénticas en las causas Juzgado de Letras de Arica, 21.1.2016, rit M-2-2016 y Juzgado de Letras de Arica, 26.1.2016, rit M-5-2016.

56 Juzgado de Letras del Trabajo de Iquique, 4.1.2016, rit M-1-2016.

57 Accatino, 2003.

${ }^{58}$ Así, por solamente dar un ejemplo, resulta pasmosa la naturalidad con la que la praxis ha entendido este ejercicio. Una resolución que sirve como paradigmática de las demás (es decir, que demuestra la ausencia de fundamentos y, por tanto, su imposible control): "Téngase por admitida demanda en procedimiento monitorio: No existiendo antecedentes suficientes para emitir pronunciamiento y de conformidad a lo dispuesto en el artículo 500 del Código del Trabajo, cítese a las partes a audiencia única de contestación, conciliación y prueba” Juzgado de Letras del Trabajo de Calama, 10.1.2017, rol M-2-2017. 
a las partes a audiencia de conciliación, contestación y prueba”. Desconocemos cuál es el criterio para llamar de inmediato a audiencia, pareciendo que se realiza fundado en la materia y, lo cierto, es que no tiene nada que ver una cosa con la otra.

Sin embargo, y pese a todo lo señalado hasta el momento, sí existe un supuesto tipo en que no parece tan descabellado llamar a audiencia, aunque preferible pareciera rechazar de plano. Es aquel caso en que la pretensión se plantea en forma equívoca y no permite al juez acoger de inmediato, ya que más allá de una cuantía cierta, no se invoca una causal determinada. En otras palabras, el procedimiento monitorio debiese plantearse en términos certeros y con peticiones extremadamente precisas, evitando fórmulas que se han convertido en excesivamente usuales como "en la cantidad mayor o menor que Us. considere pertinente”. Por tanto, no es posible sostener la petición en forma alternativa o con opciones subsidiarias.

Así, en las causas M-1-2016 y M-3-2016 sustanciadas ante el Juzgado de Letras del Trabajo de Calama se presentan dos ejemplos acerca de lo que aludimos. El demandante solicita que se consideren los hechos descritos como despido injustificado, indebido o improcedente ${ }^{59}$, sin precisar exactamente qué tipo corresponde. En este entendido, solo una mala calificación jurídica que genere la duda suficiente permitiría visos de abrir una audiencia.

Ante este panorama de duda o incertidumbre parece recurrente que los abogados presenten sus escritos acompañando documentos ${ }^{60}$. Lo cierto es que el art. 446 CT señala expresamente que el momento procesal oportuno es la audiencia preparatoria, cuestión que determinaría automáticamente que nuestro monitorio laboral es, sin duda, un monitorio “puro”. En este caso, al no existir esa audiencia, debiera ser en la única audiencia posible. Pero el funcionamiento forense ha entendido que antecedentes significa algo equivalente a lo que nuestros tribunales civiles mal entendieron mucho tiempo por comprobantes que constituyan presunción grave ${ }^{61}$ al resolver respecto de solicitudes

${ }^{59}$ Existe una importante diferencia y discusión que bien se plantea en: RoJAs, 2013, pp. 128-130.

60 Solamente es obligatorio acompañar, como requisito de procedibilidad, el acta emitida por la Inspección del Trabajo, que da cuenta de haber tratado una conciliación previa a la vía jurisdiccional. En este sentido véase cómo la causa del $1^{\circ}$ Juzgado de Letras del Trabajo de Santiago, 5.1.2016, rol M-4-2016 no prosperó por este motivo.

${ }^{61}$ En efecto, tratándose de las medidas precautorias es clásico distinguir respecto de sus presupuestos entre la exigencia del periculum in mora y la exigencia de fumus in boni juris. Pues bien, respecto del segundo presupuesto, durante mucho tiempo nuestros tribunales entendieron que detrás de ella se recogía la obligación de apoyarse en documentos que respaldaran el planteamiento cautelar. Con el paso de los años, y acogiendo una mejor lectura de la institución de las medidas cautelares, la jurisprudencia ha abierto la puerta, no sin pocos repliegues, ni sin contradicciones, a ir superando poco a poco estas exigencias derivadas de una errónea interpretación de la expresión "comprobantes", avanzando a contentarse con una apariencia de derecho, con una "presunción grave" de que el actor logrará la declaración o ejecución de su derecho, que no necesariamente deban traducirse en documentos, sino que por ejemplo, puedan extraerse del mérito de la propia presentación o del mérito de autos. De este modo, a nuestro juicio, se logra avanzar también hacia un mejor punto de equilibrio que resguarde más eficientemente el periculum in mora, la eficacia del proceso civil y la técnica de las medidas cautelares. Relacionado con este tema, y especialmente acerca de los aspectos principales a los que debiese avocarse una reforma a la tutela cautelar civil, véase: CORTEZ, 2006, pp. 521 y ss. 
de medidas precautorias (art. 288 CPC). Se abre así la posibilidad de pensar en que las demandas monitorias que no acompañan documentos no podrán prosperar. Un caso ejemplificador de este problema es el sucedido en el monitorio M-2-2016 sustanciado ante el Juzgado de Letras del Trabajo de La Serena. En este caso, lo ideal -probablemente- hubiera sido acoger el monitorio. Finalmente, el demandante no pudo acreditar la existencia de la relación laboral, pero pareciera que no le correspondiera al juez buscar un llamado a audiencia aduciendo que existen pocos documentos para fallar ${ }^{62}$.

En otro orden de ideas, otra forma de proceder, que pareciera razonable por parte de los abogados, es aquella que pretende soslayar el llamado a audiencia, correlacionando sus dichos con las exigencias legales. Así, por ejemplo en la causa M-3-2016, de 7 de enero, del Juzgado de Letras de La Serena el abogado patrocinante organizó su libelo conforme a los requerimientos normativos: exposición de los antecedentes de hecho de la relación laboral; los antecedentes referidos al término de la misma y los trámites posteriores al despido (y previo a señalar los antecedentes de derecho); el abogado narró la fundabilidad de las pretensiones, distinguiendo lo sencillo que resultaba el asunto (falta de complejidad), la ausencia de comparecencia del demandado a la audiencia de conciliación ante la Inspección del Trabajo y la existencia de impagos previsionales y del fondo de cesantía. Pero ni de este modo pudo evitar la duda. Y, en definitiva, parece corroborarse la idea que los jueces no siempre se sienten cómodos fallando sin un conocimiento acabado del asunto $^{63}$. Finalmente, se produce el efecto paradójico de esta situación: el demandado venció totalmente y sus pretensiones fueron totalmente acogidas.

En cualquier caso, no pareciera tener mucha relevancia la forma de intentar la petición con lo que resuelva el tribunal. En la causa M-4-2016 del mismo juzgado, no hubo mayor justificación a la petición y la demandante solamente aduce que cuando trató de ingresar a su lugar de trabajo, las puertas estaban cerradas y no atendieron el teléfono. Otro ejemplo necesariamente claro para acoger de inmediato el monitorio. Sin embargo, el tribunal hizo llamado a audiencia, el demandado no compareció y por efecto del art. $453 \mathrm{~N}^{\circ} 1$ inciso séptimo, del mismo modo se le tuvo por confeso. Así pues, la diferencia con la aplicación rigurosa del monitorio radica en otorgar la posibilidad de eventual defensa. El resultado, sin embargo, fue el mismo, un procedimiento sin contradicción que terminó acogiendo todas las peticiones del demandante.

${ }^{62}$ Más compleja parece la causa del Juzgado de Letras del Trabajo de Temuco, 5.1.2016, rit M-2-2016, a la que se acompañó un certificado que acreditaba la situación de encontrarse la persona jurídica demandada en un procedimiento concursal y que, finalmente, pareciera haberse acogido esta demanda inmediatamente, por esta razón. No creemos que deban tenerse en cuenta, otros antecedentes y menos circunstancias totalmente ajenas a la estricta relación laboral.

${ }^{63}$ En un ejercicio ejecutado en una forma muy parecida el Juzgado de Letras del Trabajo de Concepción sí acogió de inmediato pareciendo más razonable su decisión. Es interesante fijarse en que el escrito está organizado en prácticamente una forma idéntica y, por otra parte, la Defensoría en la ciudad de Concepción incluyó un apartado de "conclusiones". Puede consultarse todo el contenido en Juzgado de Letras del Trabajo de Concepción, 4.1.2016, rol M-4-2016. 
De modo que, en términos muy generales, observamos llamados a audiencia única en que la controversia pudiera haberse encauzado acogiendo. En algunos casos, la demandada ni tan siquiera se defiende en aquella audiencia ${ }^{64} \mathrm{y}$, en otros, el demandante debe renunciar a parte de sus pretensiones por una conciliación que pareciera resultarle perjudicial $^{65}$.

\section{El ROL DEL JUEZ: A MODO DE CONCLUSIÓN}

Ante todas estas dificultades que se observan juega un papel altamente relevante el juez. Desde la reforma a la Justicia de Familia se asentaron en nuestro entorno jurídico-cultural ciertos principios que han justificado un papel más activo del juez en el proceso.

Principios como impulso procesal de oficio, inmediación, buena fe y, en general, una exacerbada comprensión de la técnica de la oralidad como rectores del proceso ${ }^{66}$, determinan un aceptado y, a veces, preocupante poder absoluto del juez que, cual movimiento pendular perfecto, pasa de un papel totalmente pasivo en que ni de oficio realizaba actuaciones que la propia ley diáfanamente le imponía, a exagerar algunas potestades rebasando la línea de lo tolerable en la posición de tercero imparcial que se espera del mismo modo en un sistema procesal contemporáneo ${ }^{67}$.

Este funcionamiento, descrito en este trabajo, resulta adicionalmente llamativo atendida la particularidad que se predica desde hace tiempo respecto del juicio laboral: si el juez fuera activista en favor del trabajador, su intervención en el procedimiento monitorio llamando a audiencia solamente produce beneficios en el empresario, quien, junto con la dilación del procedimiento, podrá defenderse en un supuesto en el que probablemente no podía sino esperar su condena.

No podemos coincidir con este resultado que nos muestra la aplicación práctica del monitorio laboral, pues si bien puede ampararse en alguna debilidad de diseño por parte del legislador, consideramos que invierte totalmente el sentido que debe darse a un instrumento de tutela que debe honrar, antes que cualquier otro previsto en la reforma procesal laboral, el sentido de celeridad en la respuesta jurisdiccional.

${ }^{64}$ A veces, ni tan siquiera comparece a defenderse. Por ejemplo, Juzgado de Letras del Trabajo de Los Ángeles, 5.1.2016, rit M-1-2016; Juzgado de Letras del Trabajo de Temuco, 5.1.2016, rit M-1-2016.

${ }^{65}$ En parecidos términos a lo ya descrito y en consonancia a lo señalado en esta conclusión preliminar puede consultarse: Juzgado de Letras de Valparaíso, 4.1.2016, rit M-1-2016; Juzgado de Letras de Valparaíso, 4.1.2016, rit M-2-2016; Juzgado de Letras de Valparaíso, 4.1.2016, rit M-3-2016; Juzgado de Letras de Valparaíso, 4.1.2016, rit M-5-2016.

66 Palomo, 2010, pp. 327 y ss.

${ }^{67}$ Situaciones desbordadas y arbitrarias de las que hemos sostenido una lectura crítica. Véase PALOMO, 2015, pp. 381 y ss. 
No está aconteciendo perfectamente de este modo, lo que debe ser corregido por una actuación sin complejos por parte de los jueces, que no termine torciendo la propia esencia de un mecanismo que por su propia naturaleza debe estar al servicio de una tutela rápida. La actuación de los jueces que hemos descrito en las líneas precedentes se transforma en un verdadero contrasentido que en un propósito (inconfesado) de resguardar el derecho al debido proceso del demandado, ignora las cautelas que ya abriga este mecanismo y, de paso, contradice las propias actuaciones o intervenciones que, en franca oposición a esta presunta preocupación por el debido proceso, materializan no pocos jueces en el ámbito laboral, en el marco del procedimiento ordinario.

Más claro aún, si es posible. Mientras menos actividad muestren los jueces laborales en el ámbito del procedimiento monitorio, mayor coherencia mostrarán en la tutela de los derechos de los trabajadores.

\section{BiBLIOGRAFÍA}

Accatino Scagliotti, Daniela, 2003, "La Fundamentación de las sentencias: ¿un rasgo distintivo de las judicaturas modernas?", Revista de Derecho (Valdivia), volumen XV, № 2 .

Biblioteca del Congreso Nacional, 2006, "Historia de la Ley No 20.087. Sustituye el Procedimiento Laboral contemplado en el Libro V del Código del Trabajo”. Disponible en https://www.bcn.cl/historiadelaley/fileadmin/file_ley/5683/HLD_5683_37a6259cc0c1da e299a7866489dffobd.pdf [Fecha de consulta: 1.12.2017].

Biblioteca del Congreso Nacional, 2008, "Historia de la Ley No 20.260. Modifica el Libro V del Código del Trabajo y la Ley No 20.087, que establece un Nuevo Procedimiento Laboral”. Disponible en https://www.bcn.cl/historiadelaley/fileadmin/file_ley/5211/HLD_5211_37 a6259cc0c1dae299a7866489dff0bd.pdf [Fecha de consulta: 1.12.2017].

Biblioteca del Congreso Nacional, 2016, "Historia de la Ley No 20.974. Modifica normas sobre procedimiento de tutela laboral y procedimiento monitorio”. Disponible en https:// www.bcn.cl/historiadelaley/fileadmin/file_ley/5977/HLD_5977_37a6259cc0c1dae299a7 866489dffobd.pdf [Fecha de consulta: 1.12.2017].

Bonet Navarro, José, 2014, Los Procedimientos Monitorios Civiles en el Derecho Español, Cizur Menor: Thomson Reuters.

Bordalí Salamanca, Andrés, 2016, Derecho Jurisdiccional, Valdivia: Derecho Austral.

Calamandrei, Piero, 2006, El procedimiento monitorio, Buenos Aires: Librería El Foro.

Concha TApia, Robert, 2015, "Visión crítica del procedimiento monitorio laboral a la luz del debido proceso. Problemas prácticos y su posible solución”, Revista de Derecho Universidad San Sebastián, volumen 21.

Corporación administrativa del Poder Judicial, 2015, Labor jurisdiccional Tribunales de primera instancia. Disponible en http://www.pjud.cl/documents/10179/4632630/3.3+ Labor +Jurisdiccional + de + Tribunales + de + Primera + Instancia +2015.PDF/8c207268-f25a4a49-a094-a553c29cc393 [Fecha de consulta: 1.12.2017].

Cortez Matcovich, Gonzalo, 2006, "La reforma del proceso cautelar", en José Silva Prado y otros (Editores), Justicia civil y comercial: una reforma pendiente. Bases para el diseño de la reforma procesal civil, Santiago, P. Universidad Católica de Chile, Instituto Libertad y Desarrollo y Universidad Autónoma de Madrid, pp. 521-551. 
Chiovenda, Giuseppe, 1925, Principios de Derecho Procesal Civil, (3 $3^{\text {a }}$ edición), Tomo I, Madrid: Editorial Reus S.A.

De la Oliva Santos, Andrés, 2004, "Tres tópicos falsos sobre el derecho y un colofón para juristas", Reforma judicial: Revista Mexicana de Justicia, Versión electrónica, No 4.

Delgado Castro, Jordi y Vallespín Pérez, David, 2016, "Problemas de diseño del procedimiento monitorio civil chileno", Revista de Derecho (Coquimbo), volumen 23, No 2 .

Delgado Castro, Jordi, 2015, "El (anti)monitorio laboral: una criticable creación original”, en Diego Palomo Vélez, Proceso y Justicia laboral: Lecturas a contracorriente, Santiago, Ediciones Jurídicas de Santiago, pp. 273-301.

Delgado Castro, Jordi, 2015, "Estudios a propósito de la llegada del monitorio civil a Chile, Santiago: Ediciones Jurídcas de Santiago.

Gamonal Contreras, Sergio, 2013, "El principio de protección del trabajador en la Constitución chilena", Estudios Constitucionales, volumen 11, Nº 1 .

García Cano, Sandra, 2013, Estudio sobre el proceso monitorio europeo, Cizur Menor: Aranzadi Thomson Reuters.

Gutiérrez-Alviz y Conradi, Faustino, 1978, El procedimiento monitorio. Estudio de Derecho comparado, Sevilla: Anales de la Universidad Hispalense.

Hernández Jara, Patricio, 2012, Procedimiento monitorio laboral. Estudio crítico a la luz del debido proceso y del derecho comparado, Santiago: Librotecnia.

INE, 2016, "Justicia, informe anual". Disponible en http://www.ine.cl/estadisticas/sociales/ justicia [Fecha de consulta: 1.12.2017].

INE, 2017, "Justicia, informe anual 2016". Disponible en http://www.ine.cl/estadisticas/sociales/ justicia [Fecha de consulta: 1.12.2017].

Letelier Loyola, Enrique, 2015, "Reflexiones entorno a la oposición del deudor en el procedimiento monitorio propuesto para Chile", en Jordi Delgado Castro (Director) Estudios a propósito de la llegada del monitorio civil a Chile, Santiago: Ediciones Jurídcas de Santiago.

Lorca Navarrete, Antonio María, 1988, El procedimiento monitorio civil, San Sebastián: Instituto Vasco de Derecho Procesal.

Lorca Navarrete, Antonio María, 2000, El proceso monitorio en la nueva Ley de Enjuiciamiento Civil con especial referencia al proceso monitorio en materia de propiedad horizontal, Madrid: Dykinson.

Méndez Tomás, Rosa María, 2010, El proceso monitorio, Barcelona: J. M. Bosch.

Montero Aroca, Juan, 2013, Derecho Jurisdiccional II. Proceso civil, Valencia: Tirant lo Blanch.

Navarro Albiña, René, 2011, El juicio monitorio en el Derecho procesal laboral chileno. Dogmática y praxis, Santiago: Ediciones Jurídicas de Santiago.

Nieva Fenoll, Jordi, 2015, Derecho Procesal II. Proceso civil, Madrid: Marcial Pons.

Nieva, J.; Rivera, R.; Colmenares, C. y Correa, J., 2015, El procedimiento monitorio en América Latina: Pasado, presente y futuro, Bogotá, Ed. Temis.

Orellana Torres, Fernando, 2009, Comentarios al nuevo proceso laboral, Santiago: Librotecnia.

Orellana Torres, Fernando, 2010, "Cuestiones procesales del procedimiento monitorio regulado en el Código del Trabajo y la forma de proceder en los casos de aplicarse las normas sobre régimen de subcontratación", Revista Chilena de Derecho del trabajo y de la Seguridad Social, volumen $1, \mathrm{~N}^{\circ} 2$.

Ortells Ramos, Manuel, 2010, "Formas del procedimiento y garantías fundamentales del proceso civil”, Revista Ius et Praxis, volumen 16, No 1 .

Palavecino Cáceres, Claudio y Ramírez Soto, Cristian, 2010, "Examen crítico de la sentencia anticipada en el procedimiento monitorio laboral", Revista chilena del trabajo y de la seguridad social, volumen $1, \mathrm{~N}^{\circ} 2$. 
Palavecino CÁceres, Claudio, 2011, "El retorno del inquisidor. Las potestades judiciales en materia probatoria en el procedimiento laboral chileno", Revista Latinoamericana de Derecho Social, $\mathrm{N}^{\mathrm{o}} 13$.

Palomo Vélez, Diego y Matamala Souper, Pedro, 2012, "Los problemas de los poderes ex oficio del juez laboral. Ahora a propósito de la potestad conciliatoria”, Revista Ius et Praxis, volumen $18, \mathrm{~N}^{\circ} 1$.

Palomo Vélez, Diego, 2010, “Proceso civil oral: ¿qué modelo de juez requiere?”, en Diego Palomo Vélez (compilador), Reforma procesal civil, oralidad y poderes del juez, Santiago, Ed. Abeledo Perrot, pp. 327-354.

Palomo Vélez, Diego, 2015, "Proceso laboral chileno y la tutela judicial efectiva: sobre el difícil avance hacia un mejor modelo que no sacrifique los postulados elementales del debido proceso", en Diego Palomo Vélez (coordinador), Proceso y Justicia laboral: lecturas a contracorriente, Santiago, Ed. Jurídicas de Santiago, pp. 381-429.

Palomo Vélez, Rodrigo, 2007, "El rol de los principios en la aplicación del Derecho del Trabajo. Antecedentes conceptuales sobre el estado del arte en Chile", Revista Laboral Chilena, noviembre 2007.

Pereira Lagos, Rafael, 2008, El procedimento monitorio laboral, Santiago: Abeledo Perrot LegalPublishing.

Pérez Ragone, Álvaro y Orellana Torres, Fernando, 2007, "Radiografía de la rebeldía en el proceso civil: Tópicos hacia una adecuada regulación en la nueva justicia civil”, Revista Ius et Praxis, volumen 13, $\mathrm{N}^{\circ} 2$.

Pérez Ragone, Álvaro, 2006, "En torno al procedimiento monitorio desde el derecho procesal comparado europeo: caracterización, elementos esenciales y accidentales", Revista de Derecho (Valdivia), volumen 19, $\mathrm{N}^{\circ} 1$.

Planchadell Gargallo, Andrea, 2015, La tutela del crédito en el proceso monitorio, Madrid: La Ley.

Rechberger, Walter, y Kodek, Georg, 2001, Order for payment in European Union/L'injonction de payer dans l'Union Européenne, The Hague: Kluver.

Rojas MiÑo, Irene, 2013, "La naturaleza jurídica de la indemnización por término de contrato de trabajo en el ordenamiento laboral chileno", Revista de Derecho (Valparaíso), No 41.

Tomás y Valiente, Francisco, 1960, "Estudio histórico-jurídico del proceso monitorio", Revista de Derecho Procesal, $\mathrm{N}^{\circ} 1$.

Ugarte Cataldo, José Luis, 2008, "Inspección del Trabajo en Chile: Vicisitudes y desafíos", Revista Latinoamericana de Derecho Social, No 6.

Normas jurídicas citadas

Mensaje de la Presidenta de la República con el que inicia un proyecto de ley que modifica el libro V del Código del Trabajo y la Ley $\mathrm{N}^{\circ} 20.087$, que establece un nuevo procedimiento laboral. Mensaje No 455-354, 2007. 